\title{
Editorial: Predicting and Managing Climate-Driven Range Shifts in Plants
}

\author{
Emily V. Moran ${ }^{1 *}$, Wilfried Thuiller ${ }^{2}$, Amy L. Angert ${ }^{3}$ and Marta Benito Garzón ${ }^{4}$ \\ ${ }^{1}$ Department of Life and Environmental Sciences, University of California, Merced, Merced, CA, United States, ${ }^{2}$ Université \\ Grenoble Alpes, Université Savoie Mont Blanc, CNRS, LECA, Grenoble, France, ${ }^{3}$ Department of Botany and Zoology, \\ University of British Columbia, Vancouver, BC, Canada, ${ }^{4}$ INRAE UMR1202 Biodiversité Gènes et Communautés (BIOGECO), \\ Pessac, France
}

Keywords: climate change, range shift, plant, species distribution modeling, demography, intraspecific variation, species interactions

\section{Editorial on the Research Topic}

\section{Predicting and Managing Climate-Driven Range Shifts in Plants}

Plants' geographic ranges will shift in response to climate change; already some shifts have been documented (Lenoir et al., 2008; Parmesan and Hanley, 2015; Zu et al., 2021). Plants face a number

OPEN ACCESS

Edited by:

Rubén G. Mateo,

Autonomous University of

Madrid, Spain

Reviewed by:

Daniel Scherrer,

Swiss Federal Institute for Forest, Snow and Landscape Research WSL), Switzerland

Helena Hespanhol,

Centro de Investigacao em Biodiversidade e Recursos Geneticos

(CIBIO-InBIO), Portugal Antoine Adde,

University of Lausanne, Switzerland

*Correspondence: Emily V. Moran emoran5@ucmerced.edu

Specialty section:

This article was submitted to Biogeography and Macroecology, a section of the journal Frontiers in Ecology and Evolution

Received: 16 January 2022 Accepted: 07 February 2022 Published: 28 February 2022

Citation:

Moran EV, Thuiller W, Angert AL and Benito Garzón M (2022) Editorial: Predicting and Managing Climate-Driven Range Shifts in Plants. Front. Ecol. Evol. 10:856213. doi: 10.3389/fevo.2022.856213 of challenges to tracking climate, including dispersal (e.g., seed number, dispersal distance, etc.) and establishment limitations (i.e., unsuitable soil or competition from existing vegetation) (Van Grunsven et al., 2010; Svenning et al., 2014; Lustenhouwer et al., 2017; Thuiller et al., 2019; Sharma et al., 2022). It is also challenging to predict where suitable future habitats will be, given uncertainties in biodiversity models (Thuiller et al., 2019) and climate projections (IPCC, 2013). Inter- and intra-specific variation in climate sensitivity (Angert et al., 2011; Benito Garzón et al., 2019; DeMarche et al., 2019) and the possibility of evolutionary responses (Bush et al., 2016; Cotto et al., 2017; Moran, 2020) particularly complicate the latter. The goal of this Research Topic was to highlight the importance of understanding plant range shifts, to review what is known, and to identify key knowledge gaps.

Several studies used species distribution modeling (SDM) to examine potential range shifts. Zhang et al. found that while suitable area worldwide for the vine Akebia quinata might increase up to $50 \%$ by 2080 , this was mostly driven by increased suitability where the species is introduced; suitable native habitat in Asia was projected to decline. Brodie et al. modeled the range of the succulent tree Aloidendron dichotomum. The species likely expanded poleward after the last glacial maximum, consistent with observed genetic variation. Suitable habitat could shift eastward toward the summer-rainfall areas of South Africa by 2070, but range shift rates needed to track habitat were substantial and many species are dispersal-limited. Moeller et al. found that there is a $100-150 \mathrm{~km}$ gap in suitable habitat between the Appalachian and Allegheny mountains both for four species endemic to the Southern Appalachians and for four more widely-distributed species. However, the endemic species never crossed this gap and thus have unfilled suitable habitat to the north. Since these endemics are projected to have declining habitat suitability in their native range, assisted migration across the gap might be necessary to conserve them. Similarly, Semenchuck et al. found that the representation of Austrian endemic plant species in protected areas was projected to decline to $1 / 3$ by 2080 in both RCP 4.5 and RCP 8.5 scenarios, with $20-30 \%$ of the species studied having zero range representation in protected areas by that date.

While SDMs are relatively simple to implement, concerns have been raised regarding the inherent assumption that species are well-adapted to current conditions (Ibanez et al., 2006; Browne et al., 2019), omission of species interactions (Davis et al., 1998), and ability to project habitat suitability outside the current range of conditions (Williams and Jackson, 2007; Merow et al., 2014). Charney et al. tested 11 algorithms using subsets of forest inventory data for 108 North American tree species. When extrapolating from one region to another, a substantial proportion of algorithms performed worse than random. Data integration approaches that draw from the full 
species range often improve performance of SDMs (Chevalier et al., 2021) but novel future climate space or climate-edaphic combinations cannot be included in the initial model fitting. As Charney et al. noted, the use of more process-based or hybrid models might help to address this issue.

Petit et al. used a process-based model simulating physiological climate responses in five European tree species to estimate mortality risk. They found that, despite positive effects of higher $\mathrm{CO}_{2}$ on carbon assimilation and water use efficiency, risks of extinction for "genetic conservation units" are similar to or higher than those calculated from SDMs. Qiu et al. used a combination of forest inventory data and demographic data from the MASTIF network to examine demographic sensitivity to climatic factors and forest structure. They found that many life stages, especially fecundity, were sensitive to temperature, but that responses to other factors varied substantially. The niche estimated from adult distributions likely reflects past recruitment conditions rather than current ones. A shift in the distribution of life stages was also observed by White et al. who found that reduced stream-flow in an Australian watershed was linked to fewer juveniles relative to adult riparian trees in low-rainfall areas but more juveniles in high-rainfall areas, where more exposed sediment may have allowed more seedling recruitment.

Experiments that measure growth responses to different climate conditions can also provide important information regarding the sensitivity of locally adapted populations to climate change (Angert et al., 2011; Leites et al., 2012; Moran et al., 2017b; Arnold et al., 2019). Hallingbäck et al. used Scots pine provenance experiments to examine sensitivity of growth to climate at its northern and southern range limits. They found that factors strongly affecting growth differ and that, while moderate transfer distances have little effect on growth, local seed-sources can exhibit lower growth than non-local sources. Growth was predicted to increase at Nordic sites and in northern Spain, but decrease in southern Spain. However, a shorter tree is not necessarily less fit, as conservative growth strategies can be adaptive (Moran et al., 2017a).

The two final papers in the collection synthesized broadscale patterns. Zettlemoyer and Peterson examined how plasticity

\section{REFERENCES}

Angert, A. L., Sheth, S. N., and Paul, J. R. (2011). Incorporating populationlevel variation in thermal performance into predictions of geographic range shifts. Integr. Compar. Biol. 51, 733-750. doi: 10.1093/icb/ icr048

Arnold, P. A., Kruuk, L. E. B., and Nicotra, A. B. (2019). How to analyse plant phenotypic plasticity in response to a changing climate. N. Phytol. 222, 1235-1241. doi: 10.1111/nph.15656

Benito Garzón, M., Robson, T. M., and Hampe, A. (2019). DTraitSDMs: species distribution models that account for local adaptation and phenotypic plasticity. N. Phytol. 222, 1757-1765. doi: 10.1111/nph. 15716

Browne, L., Wright, J. W., Fitz-Gibbon, S., Gugger, P. F., and Sork, V. L. (2019). Adaptational lag to temperature in valley oak (Quercus lobata) can be mitigated by genome-informed assisted gene flow. Proc. Natl. Acad. Sci. U.S.A. 116, 25179-25185. doi: 10.1073/pnas.1908771116 in phenology is likely to affect species' adjustment to climate change. They found that plasticity is usually adaptive, and that while plasticity did not generally differ with range position, when it did edge populations tended to be more plastic. This suggests that plasticity is more likely to promote than hinder range shifts, though direct tests are needed. Shay et al. reviewed rules governing plant species ranges and what this might tell us about climate responses. Five potential rules were supported by multiple studies, including "range limits often coincide with [abiotic] niche limits," "biotic interactions often set range limits," and "smaller ranges tend to be more vulnerable." These rules suggested corresponding conservation actions.

While much attention has been paid to direct climate impacts on species ranges, these papers and others indicate other important factors. Biotic interactions will likely affect both local persistence and colonization, as will physical barriers to dispersal. Life-stages may also be affected differently by climate shifts. A particularly important issue in research evident both in this collection and overall is the northern temperate zone bias; highly biodiverse equatorial regions including tropical rainforests have received much less attention regarding how climate change impacts on species' ranges (Feeley et al., 2017; Sheldon, 2019). Non-seed plants are also seldom studied. All these topics are deserving of further research effort, and studies integrating approaches to test impacts of multiple factors are particularly needed.

\section{AUTHOR CONTRIBUTIONS}

EVM wrote the initial draft of this manuscript. All authors listed have made a substantial, direct, and intellectual contribution to the work and approved it for publication.

\section{ACKNOWLEDGMENTS}

Thank you to all the authors who contributed a manuscript to this special topic.
Bush, A., Mokany, K., Catullo, R., Hoffmann, A., Kellermann, V., Sgr,ò, C., et al. (2016). Incorporating evolutionary adaptation in species distribution modelling reduces projected vulnerability to climate change. Ecol. Lett. 19, 1468-1478. doi: 10.1111/ele.12696

Chevalier, M., Broennimann, O., Cornuault, J., and Guisan, A. (2021). Data integration methods to account for spatial niche truncation effects in regional projections of species distribution. Ecol. Appl. 31:e02427. doi: 10.1002/ eap. 2427

Cotto, O., Wessely, J., Georges, D., Klonner, G., Schmid, M., Dullinger, S., et al. (2017). A dynamic eco-evolutionary model predicts slow response of alpine plants to climate warming. Nat. Commun. 8:15399. doi: 10.1038/ncomms15399

Davis, A. J., Jenkinson, L. S., Lawton, J. H., Shorrocks, B., and Wood, S. (1998). Making mistakes when predicting shifts in species range in response to global warming. Nature 391, 783-786. doi: 10.1038/35842

DeMarche, M. L., Doak, D. F., and Morris, W. F. (2019). Incorporating local adaptation into forecasts of species' distribution and abundance under climate change. Global Change Biol. 25, 775-793. doi: 10.1111/gcb.14562 
Feeley, K. J., Stroud, J. T., and Perez, T. M. (2017). Most 'global' reviews of species' responses to climate change are not truly global. Diversity Distrib. 23, 231-234. doi: 10.1111/ddi.12517

Ibanez, I., Clark, J. S., Dietze, M., Feeley, K., Hersh, M., LaDeau, S., et al. (2006). Predicting biodiversity change: outside the climate envelope, beyond the species-area curve. Ecology 87, 1896-1906. doi: 10.1890/0012-9658(2006)871896:PBCOTC2.0.CO;2

IPCC (2013). Climate change 2013: The Physical Science Basis. Contribution of Working Group I to the Fifth Assessment Report of the Intergovernmental Panel on Climate Change. Cambridge and New York: Cambridge University Press.

Leites, L. P., Rehfeldt, G. E., Robinson, A. P., Crookston, N. L., and Jaquish, B. (2012). Possibilities and limitations of using historic provenance tests to infer forest species growth responses to climate change. Natural Resource Modeling 25, 409-433. doi: 10.1111/j.1939-7445.2012.00129.x

Lenoir, J., Gégout, J. C., Marquet, P. A., Ruffray, P., de, and Brisse, H. (2008). A significant upward shift in plant species optimum elevation during the 20th century. Science 320, 1768-1771. doi: 10.1126/science.1156831

Lustenhouwer, N., Moran, E. V., and Levine, J. M. (2017). Trait correlations equalize spread rates across plant life histories. Global Ecol. Biogeogr. 26, 1398-1407. doi: 10.1111/geb.12662

Merow, C., Smith, M. J., Edwards Jr, T. C., Guisan, A., McMahon, S. M., Normand, S., et al. (2014). What do we gain from simplicity versus complexity in species distribution models? Ecography 37, 1267-1281. doi: 10.1111/ecog.00845

Moran, E. V. (2020). Simulating the effects of local adaptation and life history on the ability of plants to track climate shifts. AoB PLANTS 12:plaa008. doi: 10.1093/aobpla/plaa008

Moran, E. V., Lauder, J., Musser, C., Stathos, A., and Shu, M. J. (2017a). The genetics of drought tolerance in conifers. N. Phytol. 216, 1034-1048. doi: $10.1111 /$ nph. 14774

Moran, E. V., Reid, A., and Levine, J. M. (2017b). Adaptation to climate along elevation gradients in invasive Solidago canadensis. PLoS ONE 12:e0185539. doi: 10.1371/journal.pone.0185539

Parmesan, C., and Hanley, M. E. (2015). Plants and climate change: complexities and surprises. Annals Botany 116, 849-864. doi: 10.1093/ $\mathrm{aob} / \mathrm{mcv} 169$

Sharma, S., Andrus, R., Bergeron, Y., Bogdziewicz, M., Bragg, D. C., Brockway, D., et al. (2022). North American tree migration paced by climate in the West, lagging in the East. Proc. Natl. Acad. Sci. U.S.A. 119:e2116691118. doi: 10.1073/pnas.2116691118
Sheldon, K. S. (2019). Climate change in the tropics: ecological and evolutionary responses at low latitudes. Annu. Rev. Ecol. Evol. Syst. 50, 303-333. doi: 10.1146/annurev-ecolsys-110218-025005

Svenning, J.-C., Gravel, D., Holt, R. D., Schurr, F. M., Thuiller, W., Münkemüller, T., et al. (2014). The influence of interspecific interactions on species range expansion rates. Ecography 37, 1198-1209. doi: 10.1111/j.1600-0587.2013.00574.x

Thuiller, W., Guéguen, M., Renaud, J., Karger, D. N., and Zimmermann, N. E. (2019). Uncertainty in ensembles of global biodiversity scenarios. Nat. Commun. 10:1446. doi: 10.1038/s41467-019-09519-w

Van Grunsven, R. H. A., Van Der Putten, W. H., Martijn Bezemer, T., Berendse, F., and Veenendaal, E. M. (2010). Plant-soil interactions in the expansion and native range of a poleward shifting plant species. Global Change Biol. 16, 380-385. doi: 10.1111/j.1365-2486.2009.01996.x

Williams, J. W., and Jackson, S. T. (2007). Novel climates, no-analog communities, and ecological surprises. Front. Ecol. Environ. 5, 475-482. doi: 10.1890/ 070037

Zu, K., Wang, Z., Zhu, X., Lenoir, J., Shrestha, N., Lyu, T., et al. (2021). Upward shift and elevational range contractions of subtropical mountain plants in response to climate change. Sci. Total Environ. 783:146896. doi: 10.1016/j.scitotenv.2021.146896

Conflict of Interest: The authors declare that the research was conducted in the absence of any commercial or financial relationships that could be construed as a potential conflict of interest.

Publisher's Note: All claims expressed in this article are solely those of the authors and do not necessarily represent those of their affiliated organizations, or those of the publisher, the editors and the reviewers. Any product that may be evaluated in this article, or claim that may be made by its manufacturer, is not guaranteed or endorsed by the publisher.

Copyright $\odot 2022$ Moran, Thuiller, Angert and Benito Garzón. This is an open-access article distributed under the terms of the Creative Commons Attribution License (CC $B Y)$. The use, distribution or reproduction in other forums is permitted, provided the original author(s) and the copyright owner(s) are credited and that the original publication in this journal is cited, in accordance with accepted academic practice. No use, distribution or reproduction is permitted which does not comply with these terms. 